
Digitized by the Internet Archive in 2012 with funding from

Agriculture and Agri-Food Canada - Agriculture et Agroalimentaire Canada 


\section{Control of}

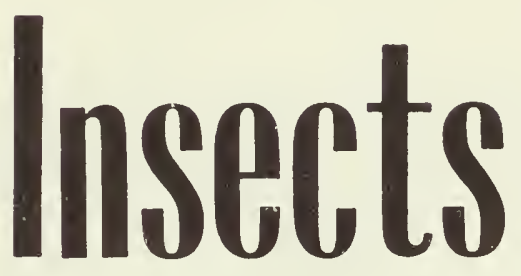

on House Plants

by G. G. DUSTAN

SCIENCE SERVICE - ENTOMOLOGY DIVISION CANADA DEPARTMENT OF AGRICULTURE

$630 \cdot 4$

(3)

p9q7

C. 3 .

QRIOTHEOUE CANAOICULTURE LIBRARY

LE L'AGAICULTURE 


\title{
CONTROL OF INSECTS ON HOUSE PLANTS
}

\author{
G. G. Dustan \\ Entomology Laboratory \\ Vineland Station, Ont.
}

The proper management of house plants will do much to prevent injury from insect pests. Keeping the humidity as high as possible makes conditions less favorable for red spider mites and scale insects. New plants and cuttings should be carefully inspected; if they are infested with insects they should be discarded, or kept away from other plants until the insects have been eliminated.

Washing plants periodically, preferably with soap solution, one or two ounces of a soft soap per gallon of rain water, also helps to keep them free from insects. Apply the soap solution with a syringe, soft brush or sponge, or by dipping, then rinse the plants off with clear water.

\section{Contact Sprays or Insecticides}

A number of insecticides, for example, nicotine, malathion, pyrethrum and derris (rotenone) extracts, and oil emulsions, are available for controlling insects on plants. In using these materials follow the manufacturers' directions carefully. Malathion, available as a dust, spray powder, or emulsion, gives good control of most insects and mites on house plants. Malathion may injure some tender plants such as Boston and maidenhair ferns, crassula and petunia.

Commercial summer oil sprays ready for dilution may be purchased, or kerosene emulsion may be prepared as follows: To $5 \mathrm{oz}$. of hot water add $1 \mathrm{oz}$. of a soft soap, preferably linseed oil soap, and stir until dissolved; then while still stirring pour in slowly $10 \mathrm{oz}$. of kerosene. Churn the mixture thoroughly or beat with an egg beater to give a creamy emulsion. For use, dilute this mixture at the rate of $3 \mathrm{oz}$. per gallon of water and add $1 / 4 \mathrm{oz}$. (2 teaspoonfuls) of nicotine sulphate. The oil sprays are particularly effective against mealybugs, scale insects and red spider mites, but must be used carefully and not too frequently to avoid injury to the foliage of some plants, especially ferns. It is a good plan to wash the plants with clear water about two hours after using an oil spray. Furthermore, after using any insecticide do not place the plants in direct sunlight for several hours.

Caution: Most insecticides are highly poisonous and must be used carefully. Avoid spilling and breathing the spray or dust. When dipping plants, wear rubber gloves.

\section{Common Pests}

Plant Lice or Aphids: These are small, green, reddish-brown, or black 
soft-bodied insects with faïly long legs. They are usually wingless. They cluster on the tender tips of the plant and on the undersides of the leaves, where they suck the sap and cause curling of the infested parts. In addition, they discharge a sticky material called honeydew. The simplest control is to spray or dip the plants with any of the contact insecticides named above, except oil, following the directions on the container. Satisfactory mixtures are one teaspoonful of nicotine sulphate to one gallon of water to which has been added an ounce of soap previously dissolved in a little hot water, or one teaspoonful of malathion emulsion in one gallon of water.

Mealybugs: Mealybugs are common on rose, fuchsia, geranium, palm, oleander, coleus and some other plants. They are relatively large, sluggish insects of oval shape and can readily be identified by the white waxy covering on the body. The young crawl about for a time after hatching, then settle down, often in clusters, and start sucking the sap. The waxy covering makes them difficult to kill and persistence is necessary to obtain good control. The following procedure is recommended:

Pick off any very heavily infested leaves and burn them. Loosen the large clusters of insects with a toothpick or sharpened match; then wash off as many as possible with a strong stream of water. Next, spray or dip the plant with (a) malathion emulsion, one teaspoonful per gallon of water, (b) nicotine-soap solution, one and one-quarter teaspoonfuls of nicotine sulphate and one ounce of soap per gallon of water, or (c) a pyrethrum-derris spray, and repeat the application at weekly intervals until not one mealybug can be found. Oil sprays with the addition of nicotine sulphate are more effective than nicotine sulphate and soap, but are more likely to injure the plants and should be washed off within two hours.

Scale Insects: These are scale-like, stationary insects usually brown in color and round, oval or oyster-like in shape. They commonly attack fern, palm, croton, ivy, oleander, cactus and rubber plant.

Scale insects are even more difficult to control than mealybugs because of their tough waxy armor. The young can be killed before they have protected themselves with the scale covering, but it is often necessary to spray from three to five times at weekly intervals to kill all the newly hatched forms. Malathion, the oil-nicotine spray, or nicotine-soap, as recommended for mealybugs, may be used.

Many old scales can be removed from palm, rubber and other plants with tough leaves by scrubbing with a soft brush soaked in the nicotine-soap mixture. or by pricking them off with a needle.

Whitefly: The adults of this pest are small, snow-white insects which fly about when disturbed. They lay their eggs on the undersides of the leaves and these hatch into small, oval, gray insects which insert their beaks into the tissue and seldom move from one spot. They secrete a sticky honeydew in which a black fungus grows, giving the plants a sooty appearance.

The pyrethrum-derris spray, malathion, and nicotine-soap mixture as recommended for aphids gives control if applications are repeated three or four times at weekly intervals. The spray usually does not kill many of the adults; therefore, before treating, remove the plant to a room away from other plants, and, before bringing it back, shake off any remaining adults.

Two-spotted Spider Mite: This serious pest of house plants is sometimes called the common red spider. These mites are barely visible to the naked eye and vary in color from yellow to green or red. They lay small, pearl-like eggs. They 
sometimes occur in large numbers on the undersides of the leaves, especially where the plants are grown in a dry atmosphere, and ca use the foliage to turn yellow and mottled. They make a fine web, under which they feed, and heavily infested plants may have conspicuous masses of webbing over and between infested leaves.

Heavily infested house plants should be destroyed, as control is difficult after the leaves are covered with webbing. Frequent syringing of the undersides of the leaves with a strong stream of water usually controls light infestations. To control heavier infestations, spray with malathion or one of the derris (rotenone) sprays two or three times at intervals of about four days, or give one or two thorough applications of the oil spray. Nicotine sulphate does not kill them.

Other Mites: Two other species of mites, the flat mite and the pallid or cyclamen mite, sometimes infest cyclamen, African violet and ivy. Both mites are very tiny and difficult to detect without the aid of a microscope. The flat mite feeds chiefly on the undersides of the leaves and causes mottling similar to injury by the two-spotted spider mite. Control measures for the flat mite are the same as for the two-spotted spider mite. Lightly dusting all parts of the plant with sulphur dust also controls the flat mite, but not the cyclamen mite.

The cyclamen mite confines its feeding almost entirely to the soft, tender growth of opening leaves and buds, and to flower parts, causing deformed, curled leaves, and streaked blossom petals. Heavily infested plants should be destroyed. Regular spraying with a derris spray every two or three weeks kills exposed mites and usually prevents serious injury. To eliminate an infestation, immerse the plant, pot and all, in water at $110^{\circ} \mathrm{F}$. for 15 minutes. The temperature has to be exact to be effective and to avoid plant injury. The larger the volume of water the easier it is to maintain the proper temperature.

Soil Pests: Small white maggots are sometimes abundant in the soil of house plants. These are the young of small black flies called fungus gnats, which fly around the plants or rest on the leaves but cause no injury. The maggots seldom attack the roots of the plants, but if their presence is annoying they can be reduced in numbers by thoroughly soaking the soil with (a) malathion, one teaspoonful per gallon of water, (b) nicotine sulphate, one teaspoonful per gallon of water, or (c) strong soap solution made by dissolving one-quarter pound of soap in one gallon of water. Use about a cupful to a 6 -inch pot, or place the pot for about an hour in a pail containing just enough of the liquid to cover the top of the soil.

Small white grubs of the black vine weevil occasionally attack and feed on the roots of the potted plants, especially primula, begonia, cyclamen, and ferns. If a plant seems unthrifty and remains stunted, the soil about the roots should be examined and replaced with fresh soil if grubs are found.

Earthworms sometimes disturb the root systems of potted plants by their tunnelings. Dusting the soil with hydrated lime and then watering it in usually kills the worms.

Identification of Insects: When in doubt as to what pest is injuring the plant, send specimens of the injured parts, slightly moistened and wrapped in wax paper in a box, to the Entomology Laboratory, Canada Department of Agriculture, Science Service Building, Ottawa. Enclose a note giving the name and address of the sender and the name of the plant. Mail with "Canada Department of Agriculture" in the address may be sent postage-free. 